\title{
Microbiome research potential for developing holistic approaches to improve refugee health
}

\author{
Mohammad Ahsan Fuzail ${ }^{1}$, Bilal Ahmed ${ }^{1}$, Daniel L. Burke², Amanda Hylland Spjeldnæs ${ }^{3}$, Masako Horino ${ }^{4}$, Carly Ching ${ }^{1}$, \\ Muhammad Hamid Zaman ${ }^{1}$ \\ 1 Department of Biomedical Engineering, Boston University, ${ }^{2}$ Department of Biochemistry and Molecular Biology, Boston University, ${ }^{3}$ Department of \\ Global Health and Community Medicine, University of Oslo, ${ }^{4}$ Department of International Health, Johns Hopkins Bloomberg School of Public Health; \\ Department of Health, United Nations Relief and Works Agency for the Palestine Refugees in the Near East \\ Keywords: antibiotic resistance, microbiome, epidemic, refugee health \\ https://doi.org/10.29392/001c.28997
}

\section{Journal of Global Health Reports}

Vol. 5, 2021

\begin{abstract}
Morbidity from disease is increasingly being understood as dependent on wellbeing of the ecosystem, as opposed to an isolated element. However, the combined burden of disequilibrium of the gut microbiome ecosystem - which can facilitate proliferation of antimicrobial resistance (AMR) - is not well understood. The gap in knowledge grows when considering regions, such as the Gaza Strip, where the population continues to experience recurrent conflicts, movement restrictions, and high rates of poverty, food insecurity and unemployment. ${ }^{1}$ The concurrent rise of gut microbiome disequilibrium, AMR proliferation, and displacement of populations globally - combined with lack of data - poses significant but unknown risk to public health, in displaced and host communities alike. Examining the current landscape of research, and existing gaps solidifies the need for interdisciplinary perspectives to address AMR through exploration of the gut microbiome. This holistic approach can help account for the political, socio-economic, and material factors, in the context of regions experiencing conflict/war. The growing role of microbiota in health may hold answers to questions surrounding understudied conditions such as AMR, and even non-communicable or chronic diseases.
\end{abstract}

Over the millennia, microbes have formed a conditionally mutualistic relationship with humans. ${ }^{2-4}$ The indigenous human microbiome hosts several such microbial communities in biological fluids, and tissues. These microbial communities are most abundant in assortment in the gastrointestinal tract, achieving densities of up to $10^{12} \mathrm{CFU} /$ $\mathrm{ml} .^{5}$ They engage in close and complex interactions with host and environment, making the gut microbiome an area of growing exploration and interest. We now know that it is involved in immune system function, salvaging nutrients/ energy, exerting trophic effects, and protecting the host against pathogenic invasion. ${ }^{6}$ Research has shown the importance of gut microbiota in health, and development of diseases. Gut microbiota dysbiosis can increase chances for occurrence of common chronic disease like inflammatory bowel disease (IBD), ${ }^{7}$ colorectal cancer, ${ }^{8}$ and cardiovascular issues. ${ }^{9}$ Several factors can influence dysbiosis which occurs rapidly, and with lasting effects. These factors include immunodeficiency, alcohol consumption, inadequate nutrition ${ }^{10}$; and crucially, antibiotic use.

The wellbeing of gut microbiota and the of use of antibiotics is a dual-edged sword for human health. The effective but indiscriminate approach of antibiotics causes loss of commensal gut bacteria, enabling their replacement by non-mutualist bacteria, including Multi Drug Resistant Organisms (MDROs). ${ }^{11}$ This dual threat has the potential to exponentially worsen in the context of armed conflict, subsequent violent dispossession, and displacement of affected populations. The circumstances of conflict entail severe disruption of access to adequate nutrition, clean water, sanitation, shelter, and medical care. Along with forced displacement within or across borders, affected persons stand to bear an unknown, potentially high, burden of synergetic gut dysbiosis, and MDRO colonization/infection, especially in highly stressful situations. Despite the interlinked nature of these three phenomena (gut dysbiosis, AMR proliferation, forced displacement crises), limited data exists on the interaction between them, and the extent of the problem. The prevailing pandemic has shown how significantly health is connected globally; that our healthiest communities are only as healthy as the most marginalized and under-cared for. Better care for these communities begins with dedicating interdisciplinary efforts to direct holistic interventions.

\section{MICROBIOME AND AMR: CIRCUMSTANTIAL SYNCHRONY}

The advent of antibiotics nearly a century ago changed the landscape of bacterial infectious diseases and the mortality associated with them. Up until then casualties were so rampant, that from 1775-1918 more US armed personnel lost lives to infectious diseases than direct enemy actions. ${ }^{12}$ The boom in antibiotic therapeutics that followed penicillin, made it seem like bacterial infections were a concern of the past. However, it remains important to consider the evolu- 
tionary advantage of bacteria. Since before the advent of human beings, microorganisms have inevitably evolved defenses against antibiotic agents, resulting in the emergence of Multi-Drug Resistant Organisms (MDROs). ${ }^{13}$ Their ability to thwart antibiotics through chromosomal mutation, or exchange of mobile genetic elements (MGEs) like plasmids enabled bacteria to become resistant to most, if not all, antibiotics administered, and that resistance can transfer through reproduction, as well as horizontal gene transfer (HGT). ${ }^{14}$

Worryingly, the microbiome also has an environment conducive to the transfer of Antibiotic Resistance Genes (ARGs) on MGEs and through HGT. ${ }^{14,15}$ The gut antibiotic resistome consists of ARGs that are both evolutionarily distinct from known resistance genes in addition to ones identical to the pathogenic species. Both, commensal and opportunistic pathogens harbor these ARGs. Occurrence of Antimicrobial Resistance (AMR) and rising microbiota imbalances is prevalent globally, even in urban environments. ${ }^{16-19}$ Atypical from other infectious diseases, AMR can nullify antibiotic therapeutics and at once jeopardize health outcomes of easily treatable infections, ${ }^{20}$ as well as major procedures such as organ transplants, chemotherapy or surgeries. ${ }^{21}$

Several factors concurrently contribute to reduction of microbiota diversity and provide conditions that favor proliferation of MDROs. Foremost, antibiotic use impacts not just commensal gut microbiota but also leads to resistance in the population, through multiple pathways. In humans, ARGs can be acquired through meat of livestock that were given antibiotics. ${ }^{22}$ Moreover, as much as $75 \%$ of consumed antibiotics are egested unchanged in animals and humans alike. $^{23}$ These excreted antibiotics - along with ARGs then find their way into the environment through run off, or travel through sewage systems, and lead to development of AMR in both contexts. ${ }^{24}$ Resistance to antibiotics can further occur in hospital-settings, spreading directly among patients or indirectly through care providers or the environment, ${ }^{25}$ and within the community, through interaction, or co-habitation with MDRO colonized/infected persons. ${ }^{26}$

In combination with high use of antibiotics, urbanization and its impacts also aid the synergetic chaos of AMR and gut dysbiosis. Industrialized, urban cities and regions experience consistent exchange of migrants, as rural poverty drives them to seek better living conditions. ${ }^{27}$ Without proper planning for such influxes, public health issues arise and negatively impact quality of life. Crowding, low levels of physical activity, and nutritional imbalances mean that urban poor populations bear risk of communicable diseases, in coexistence with non-communicable disease prevalent in wealthy communities. ${ }^{28,29}$

AMR continues to advance, even in the gut microbiome. Further, the gut often experiences dysbiosis in parallel. Our understanding of the dynamics of both remains limited. As the COVID-19 pandemic has shown, public health surveillance, infection control and elimination, quarantine abilities, and even communication of public health/epidemiological data is critically compromised..$^{30-33}$ Similar themes define the history of AMR as an infectious disease. ${ }^{34}$ Much more concerning, however, are the potential future trajectories of AMR.
The proliferation of AMR is already causing disruption in health, nutrition, and therapeutics alike. ${ }^{35,36}$ AMR disrupts access to and delivery of healthcare even in regions with generally high income, and developed economic/health status. ${ }^{37,38}$ Meanwhile, forcibly displaced persons - and Palestinians, particularly - have limited or non-existent access to medical care. ${ }^{39,40}$ The prevailing scarcity, enforced blockade, geographic isolation, and displacement also means an increased risk of exposure to substandard, expired or counterfeited medical supplies - including antibiotics. ${ }^{41-43}$ Consequently, the situation in Gaza bears the hallmarks of having reached or even exceeded, the minimum threshold for prompt action. The prevailing COVID-19 pandemic has managed to strain the medical care systems of even well-resourced, and medically advanced nations. Considering the impact of repeated conflict, and displacement along with the added pressures of COVID-19 we believe there must be a formidable risk of burden from AMR and gut dysbiosis, which thrive in such unmonitored and under-resourced conditions. We say "must be" because part of the potential risk includes the near total void of research into the likelihood and severity of AMR and the impact of microbiome health on the same, within Palestinian and particularly, Gazan communities.

\section{FORCED DISPLACEMENT, AMR AND GUT DYSBIOSIS: CASE STUDY OF GAZA, OCCUPIED PALESTINE}

Over the past 54 years, war and conflict in Gaza have grown to disproportionately impact Palestinian civilians. The complexity of the situation is compounded by the physical restraints of Gaza, which has an area of $365 \mathrm{~km}^{2}$ - just above twice that of Washington, DC. ${ }^{44}$ A population of $2.1 \mathrm{~m}$ means the Gaza Strip, however, is four times more densely populated than Bangladesh. ${ }^{45}$ Isolation of the Gazan population enforced via militarized borders generates acute scarcity of healthcare facilities, jobs, education, and food. Despite nearly $70 \%$ of the population being refugees,${ }^{46}$ the enclave has been under land, air, and sea blockade since 2006. Consequently, the outcomes of repeat military action on Gaza - as recently as May/June 2021 - are devastating. Results from a rapids needs assessment (RNA) conducted following the recent round of assault on Gaza by CARE, ${ }^{47}$ depicts extremely worrying trends (Table 1 ).

Beyond impacting people, conflict and forced displacement also devastate the environment, infrastructure, livelihoods, and social wellbeing. As such, the crisis in Gaza, necessitates exploring the potential for negative effects of AMR, gut dysbiosis, and forced displacement simultaneously. The Internal Displacement Monitoring Centre highlights 7 aspects of life affected by forced displacement: livelihoods, education, health, security, social life, environment and access to housing and infrastructure. ${ }^{48}$ The effects on each aspect, in turn ripple through to others. In areas as densely populated as Gaza, it is important to recognize the inseparability of populated spaces from the "natural environment". ${ }^{49}$ Indeed, the health and well-being of the populace depends on the balance between both. Clean air, water, and land for instance, require upkeep of popu- 
Table 1. CARE West Bank/Gaza rapid needs assessment (RNA) summary - May/June 2021 (n=62 respondents)

\begin{tabular}{|c|c|}
\hline Survey category & Response \\
\hline Health & $\begin{array}{c}24 \% \text { w/o access to health services } \\
39 \% \text { have chronic illness }\end{array}$ \\
\hline Livelihood & $45 \%$ noted loss of income \\
\hline Shelter/Non-food Items & $\begin{array}{c}40 \% \text { without electricity } \\
44 \% \text { without water } \\
44 \% \text { reported damaged homes }\end{array}$ \\
\hline Food & $\begin{array}{c}23 \% \text { report skipping meals } \\
48 \% \text { reliant on humanitarian agencies }\end{array}$ \\
\hline
\end{tabular}

lated spaces via sanitation, sewage, electricity, and other vital infrastructure.

Examining the nature of armed conflict today, points to a key shift in strategy towards these critical facilities. Improvements in remote, unmanned, and long-range weaponry means warring powers increasingly opt for targeted strikes over mass deployment of troops. Despite the ability to effectively discriminate targets now, "duress bombing" - the targeting of civilian infrastructure - has been and is being deployed, particularly in the Middle East and North Africa. ${ }^{50-52}$ Ordinances deployed by armed forces exact heavy fatalities on affected people, then unleash secondary strife through the damage to resources, and ability to access them. Civilianization of war via duress bombing has been a key compounding factor for the population of Gaza. Examples include the illegal targeting of a United Nations Relief and Works Agency (UNRWA) shelter, a sewage plant, critical freshwater wells, flour mills, and poultry farms. ${ }^{53}$ These incidents are not isolated; in 2014 Gaza's only power plant was reportedly struck by Israeli fire. In summer of 2021, airstrikes damaged "six hospitals, nine primary healthcare centers, and a desalination plant”. ${ }^{54}$

Critically, the deterioration of vital infrastructure and industries due to strikes, ripples in parallel into the natural environment. The maintenance of human populations in any region is dependent on access to natural resources, and ability to refine them into food, products, and supplies. This dependence intensifies due to the enforced isolation of Gaza's populace. Historically, Gaza and the surrounding lands have been populated for millennia, supported by arable topography, and natural water supplies. ${ }^{55,56}$ The situation today is drastically different. Access to clean water is of paramount importance for sanitation, hygiene, irrigation, and consumption. However, safe potable water is essentially non-existent in Gaza. ${ }^{57}$ Destruction of wastewater treatment, and solid waste disposal systems, pollution, contamination, and the use of cesspits due to lack of centralized sewage all contribute to this scarcity. ${ }^{58-62}$ As such, $60-80 \%$ of domestic wastewater is discharged into the environment without treatment. ${ }^{57}$ When the Beit Lahia wastewater treatment plant flooded in March 2007, it killed 2 children, and 3 women, displaced others, damaged livestock, and farms, and forced the closure of surrounding groundwater wells due to contamination. ${ }^{63}$

Land in Gaza also suffers from conflict. The camp-villes (city camp) nature of Gaza's refugee camps and settlements have evolved from isolated, temporary settlements to the establishment, and subsequent destruction, of quasi-permanent cities. Expansion and rebuilding of residences alike causes resource deterioration, soil/ecosystem disruption, and pollution. ${ }^{58}$ Due to the physical constraints of Gaza, arable land is limited, and that which is available is under threat from increased construction and conflict. Contractors increasingly want to use green spaces in Gaza for construction projects, furthering the depletion of resources. Israel also maintains a buffer zone around Gaza, with ad hoc limits of extent. This buffer zone covers significant tracts of arable land, made completely unavailable. ${ }^{64}$ The land persistently suffers direct damage from airstrikes, shelling, or heavy-vehicle tracking - a United Nations Operational Satellite (UNOSAT) preliminary analysis found nearly 1,800 hectares of agricultural lands had been razed or heavily damaged, after the August 2014 assault on Gaza. 65

Recurring conflicts - including the most recent episode of violence in the summer of 2021 - lead to loss of precious life and also contribute to the destruction of the environment that can lead to long-range impact on the gut microbiome and proliferation of drug resistant organisms. ${ }^{66}$

Any one of the compounding factors of forced displacement would be enough to create favorable conditions for the rise of diseases including drug resistant infections, and gut dysbiosis. Indeed, refugee camps and settlements have faced outbreaks of infectious diseases including malaria, tuberculosis and HIV/AIDS, described extensively in the literature. ${ }^{67,68}$ Based on trends of preceding infectious disease outbreaks, all these conditions persisting simultaneously signifies an exceptionally high risk for synergetic AMR and gut dysbiosis.

\section{CAUSE AND EFFECT: AMR AND MICROBIOME IMBALANCE AMONG FORCIBLY DISPLACED}

The intersection of microbiome diversity, AMR, and the environment is of particular concern, where chronic exposure to conflict, the inevitable heavy metal pollution it brings, and infrastructural/environmental collapse perpetuate gut dysbiosis and AMR. ${ }^{69}$ In Gaza and beyond, interventions to resolve inter-linked issues holistically must begin by addressing the most vulnerable populations, in this case displaced persons. More specifically, forced displacement disproportionately affects pregnant persons and young children, creating a 'most vulnerable of the most vulnerable' scenario. By 2015, up to $80 \%$ of displaced people world- 
wide were women and children. ${ }^{70}$ Mortality among displaced women and children rises in line with risk of infection, malnutrition, increased stress, and burden from having to be the caretaker, and lack of access to care. ${ }^{71,72}$ The risk of complications during pregnancy and delivery, such as postpartum hemorrhage and pre-eclampsia, become exacerbated. ${ }^{73}$ Concurrently, infants face challenges from two fronts, as both malnutrition during gestation and within the first 12 months of life introduce significant risks for neonatal mortality, ${ }^{74}$ impairs physical and cognitive development, ${ }^{75,76}$ and predisposes malnourished children to endocrine and metabolic dysfunction later in life. ${ }^{77}$ The mother-to-infant transfer of microbiota in the formation of the neonate gut microbiome poses a unique threat, as reduced microfloral diversity and ARGs within the mother's microbiome during childbirth can be transmitted to the neonate. ${ }^{78}$ Indeed, low birth weight, childhood stunting, anemia, and chronic malnutrition are all associated with reduced microbiome diversity and gut dysbiosis. ${ }^{79,80}$ Reduced microfloral diversity and impaired nutrient absorption and gut metabolism due to MDRO overgrowth can exacerbate chronic malnutrition in children living in precarious, foodinsecure contexts. ${ }^{81}$ This MDRO overgrowth in turn compounds issues of diarrheal disease, poor nutrition, and impaired immunity that serve as significant sources of childhood morbidity within refugee settlements. ${ }^{82}$ The close association between AMR and gut imbalance induced morbidity suggests addressing one might have positive feedback onto the other. However, the scale, persistence, and complexity of forced displacement and AMR in that context mean that despite the problem being potentially prevalent, it remains understudied, under surveilled and on the cusp of receiving a significant leg up through the global upheaval of the past year.

Conventionally, strategies to curb AMR have been ad hoc, and populations have relied often on over-the-counter use of antibiotics in case of infections. However, overuse of antibiotics is a well-established pathway for the selection of AMR. ${ }^{83}$ The use of antibiotics and their consequences are influenced by several factors, especially in low- and middle-income countries, hosts to most of the global displaced population. Refugee populations are already at risk of acquiring resistant bacterial infections due to poor hygienic and sanitation conditions, and no access to care. Additionally, limited access to quality assured antibiotics ${ }^{84}$, unskilled/insufficient practitioners, ${ }^{85}$ self-medication, ${ }^{86}$ and a perceived need for antibiotics to cure or prevent diseases 87 all lead to an increased burden of AMR proliferation. Incomplete or inadequate filtration of waste also releases antibiotics into the natural environment, which finds its way into the food chain and compounds AMR further. The ripple effects of Explosive Remnants of War (ERWs) are evidenced in AMR proliferation as well. Due to their high stability, explosive compounds in ERWs bind readily with organic components of soil, remain deposited, and leech into the water, and biomass of the region. ${ }^{88,89}$ Heavy metals allow for selective pressure for resistance over a long period of time. This phenomenon has cascading effects not only in the proliferation of MDROs in an environment conducive to HGT, but also in nutrient uptake and non-communicable diseases involving the endocrine and digestive systems, ${ }^{90,91}$ partic- ularly for vulnerable populations within Gaza that are susceptible to nutrient deficiencies and infectious disease.

\section{CONTEMPORARY RESEARCH AND REQUIEM FOR INTERDISCIPLINARY INTERVENTION}

The Madrid Operational Framework of 2010, formulated at the first Global Consultation on Migrant Health, ${ }^{92}$ called for a host of measures intended to harmonize migrant/host population health and the host country's response. This framework included ensuring migrant health data standardization, mapping good practices, promoting standards to protect migrant right to health globally, and policy coherence among different sectors. Perhaps most importantly, it called to 'establish and support migration/health dialogues and cooperation across sectors and countries of origin, transit and destination'. Adaption of this framework to respond concurrently to gut dysbiosis and AMR, has enormous potential to improve holistic health outcomes. Current research aimed at the gut dysbiosis-AMR junction is (1) nascent but growing and yet (2) not in line with the Operational Framework's recommended measures. Generating new and crucial insight into the microbiome and its role in AMR proliferation, by accounting for potential intensity of burden depending on length of forced displacement, or the burden of colonization among 'otherwise healthy' displaced persons are just some areas for potential improvement. Despite this it is important to recognize the complexity of forced displacement and subsequent complication of conduct of ethical, transparent, and multifactorial research.

Among the few studies reporting on gut microbiome and AMR overlap in refugees, Hasler et al. ${ }^{93}$ report on newly admitted refugees in Germany, and diversity in both their microbiome and antibiotic resistome compared to resident Germans. The emergence of MDROs in people fleeing conflicts in Syria and Iraq has also been documented across medical centers in Turkey, Lebanon, and across Europe. Isolates of carbapenem-resistant Acinetobacter baumannii were identified in Syrian asylum seekers admitted to a medical facility in Adana, Italy, ${ }^{94}$ and a blaNDM-1-positive carbapenem-resistant $A$. baumannii reservoir was discovered among war-injured Syrian civilians admitted to the Tripoli Government Hospital in Lebanon. ${ }^{95}$ A review by Nellums et al. ${ }^{96}$ found AMR carriage or infection in migrants to be at $25.4 \%$ in 2319 people across 23 studies. The review, however, did not find evidence of high rates of transmission from migrant to host populations.

Vonaesch et al. ${ }^{97}$ describe how disturbance to equilibrium of the microbiome (during development, or post-antibiotic treatment) creates competition for space and nutrients through the priority effect. Following the disturbance, the first species to recolonize the gut creates scarcity of space and nutrients for other species. The paper emphasizes the competitive nature of the microbiome environment, which spells trouble considering the replacement of commensal bacteria by MDROs in the wake of antibiotic use. Vonaesch et al, voice support for an 'ecological Koch's postulates' framework, which states that morbidity is dependent on the equilibrium of the whole ecosystem, as opposed to a solitary element. 
Historically, global response to emergent disease threats have largely been reactive, and not preventive. Going ahead, reactiveness cannot be afforded, as the lessons of the COVID-19 pandemic have shown. Simultaneous gut microbiome and AMR exploration, would help develop a more nuanced approach, especially in the context of forced displacement. In Gaza for example, a preliminary or pilot study can (1) help gather foundational knowledge, (2) use newly gathered foundational knowledge to assess contextual efficacy of interventions like fecal/microbiome transplants vs. diet fortification, (3) help address larger concerns of microbiome health such as the exchange of commensal/pathogenic microbiome communities between host/refugee/immigrant populations. Further, we need not be restricted to exploring multifactorial issues through the lens of a single discipline. Increasing numbers of scholars in global health emphasize the importance of collaboration between disciplines, both natural and social sciences, when working with issues that are multifaceted, like $\mathrm{AMR}^{98}$ and gut dysbiosis. For interventions to be effective and sustainable, they need to be locally adapted to the specific social, cultural, political, and material conditions, ${ }^{99}$ and these perspectives are best achieved through qualitative research.

Fulfilling this need for adapted interventions, in turn requires an understanding of the prevailing landscape. However, intrinsic, and external factors of forced displacement raise significant barriers to research in this context. Foremost, protracted states of forced displacement have forced most asylum-seekers and refugees globally, to move into urban areas within their host nations, in search of better opportunities for livelihood and settlement. ${ }^{100}$ Here, they may face challenges with access to services, assimilation into local communities, health variability, and livelihood security ${ }^{101}$ : all of which can affect MDRO proliferation.

Further, growing antagonization of migrants, and increased employment of deterrence policies towards migrants and asylum-seekers, means that forcibly uprooted persons are less likely to participated in research projects that extract sensitive information. Indeed, this hesitancy is not unfounded as examples of data collected on refugees have been repeatedly utilized against them in detention or deportation efforts. ${ }^{102}$ With most refugees living in countries neighboring original conflicts, collection of identifiable data can further put refugees, and researchers, in the way of harm. Research in forced displacement also faces obstacles in the bureaucratic, technical, or linguistic contexts which are often politicized, and entail unequal power dynamics.

\section{CONCLUSIONS}

Despite evidence of gut dysbiosis and MDRO proliferation in stable, urban environments and through voluntary travel/migration, ${ }^{103}$ forcibly displaced persons stand to be worst hit by disease burden - whether communicable or not. Understanding and responding to these interlinked crises is complicated by ripple effects of displacement and conflict, especially in areas like Gaza. Decades of war, blockade, governance issues, and economic difficulties have rendered Gaza virtually unlivable as of this writing. We hope that this paper would foster discussion and initiative among researchers in a variety of disciplines to form research on the role of microbiome and AMR/disease burden in Gaza.

Interdisciplinary research, to explore sustainable interventions to limit further evolution and spread will need to break from traditional approaches to research in forced displacement. A starting point in this context, will be developing ethical, comprehensive, and participant-sensitive/inclusive methodology for research conducted. This robust methodology can then be deployed to assess key questions about the extent that gut dysbiosis, MDRO carriage/infection, and multifactorial deficiencies intersect long-term refugee settlements, and urban refugee populations alike.

\section{FUNDING}

None.

\section{AUTHORSHIP CONTRIBUTIONS}

All authors contributed to the writing of manuscript.

\section{COMPETING INTERESTS}

The authors completed the Unified Competing Interest form at http://www.icmje.org/disclosure-of-interest/ (available upon request from the corresponding author) and declare no conflicts of interest.

\section{CORRESPONDENCE TO:}

Mohammad A Fuzail

Department of Biomedical Engineering, Boston University College of Engineering, Boston, Massachusetts

Submitted: September 13, 2021 GMT, Accepted: September 21, 2021 GMT 


\section{REFERENCES}

1. Rosenthal FS. A comparison of health indicators and social determinants of health between Israel and the Occupied Palestinian Territories. https://doi.org/ 101080/1744169220201808037. 2020;16(3):431-447. d oi:10.1080/17441692.2020.1808037

2. Jernberg C, Löfmark S, Edlund C, Jansson JK. Longterm impacts of antibiotic exposure on the human intestinal microbiota. Microbiology.

2010;156(11):3216-3223. doi:10.1099/MIC.0.04061 8-0

3. Zarrinpar A, Chaix A, Yooseph S, Panda S. Diet and Feeding Pattern Affect the Diurnal Dynamics of the Gut Microbiome. Cell Metab. 2014;20(6):1006-1017. d oi:10.1016/I.CMET.2014.11.008

4. Willey JM, Sherwood L, Woolverton C. Prescott's Microbiology: 9th Revised Edition. 9th ed. McGraw Hill Higher Education; 2013. Accessed August 12, 2021. ht tps://www.worldcat.org/title/prescotts-microbiology9 th-revised-edition/oclc/858132905

5. Quigley EMM. Gut Bacteria in Health and Disease. Gastroenterol Hepatol(N Y). 2013;9(9):560. Accessed August 12, 2021. https://www.ncbi.nlm.nih.gov/pmc/ articles/PMC3983973/

6. Guarner F, Malagelada JR. Gut flora in health and disease. Lancet. 2003;361(9356):512-519. doi:10.101 6/S0140-6736(03)12489-0

7. Mirsepasi-Lauridsen HC, Vrankx K, Engberg J, et al. Disease-Specific Enteric Microbiome Dysbiosis in Inflammatory Bowel Disease. Front Med. 2018;0(NOV):304. doi:10.3389/FMED.2018.00304

8. Zou S, Fang L, Lee MH. Dysbiosis of gut microbiota in promoting the development of colorectal cancer. Gastroenterol Rep. 2018;6(1):1-12. doi:10.1093/GAST RO/GOX031

9. Serino M, Blasco-Baque V, Nicolas S, Burcelin R. Far from the Eyes, Close to the Heart: Dysbiosis of Gut Microbiota and Cardiovascular Consequences. Curr Cardiol Rep. 2014;16(11):1-7. doi:10.1007/s1188 6-014-0540-1

10. Das B, Nair GB. Homeostasis and dysbiosis of the gut microbiome in health and disease. J Biosci. 2019;44(5):1-8. doi:10.1007/S12038-019-9926-Y

11. Tosh PK, McDonald LC. Infection Control in the Multidrug-Resistant Era: Tending the Human Microbiome. Clin Infect Dis. 2012;54(5):707-713. doi:1 0.1093/CID/CIR899
12. VJ C. Two faces of death: fatalities from disease and combat in America's principal wars, 1775 to present. Perspect Biol Med. 2008;51(1):121-133. doi:1 $\underline{0.1353 / P B M .2008 .0005}$

13. Zaman MH. Biography of resistance: The epic battle between people and pathogens. Published online 2020 .

14. Shterzer N, Mizrahi I. The animal gut as a melting pot for horizontal gene transfer1. https://doi.org/ 101139/cjm-2015-0049. 2015;61(9):603-605. doi:10.11 39/CJM-2015-0049

15. Sommer MOA, Dantas G, Church GM. Functional Characterization of the Antibiotic Resistance Reservoir in the Human Microflora. Science. 2009;325(5944):1128-1131. doi:10.1126/SCIENCE.117 $\underline{6950}$

16. Xu Y, Guo C, Luo Y, et al. Occurrence and distribution of antibiotics, antibiotic resistance genes in the urban rivers in Beijing, China. Environ Pollut. 2016;213:833-840. doi:10.1016/J.ENVPOL.2016.03.05 4

17. Atterby C, Ramey AM, Hall GG, Järhult J, Börjesson S, Bonnedahl J. Increased prevalence of antibiotic-resistant E. coli in gulls sampled in Southcentral Alaska is associated with urban environments. $h t t p: / / d x . d o i . o r g / 103402 /$ iee.v632334. 2016;6(1). doi:10.3402/IEE.V6.32334

18. Tasnim N, Abulizi N, Pither J, Hart MM, Gibson DL. Linking the Gut Microbial Ecosystem with the Environment: Does Gut Health Depend on Where We Live? Front Microbiol. 2017;8(OCT). doi:10.3389/FMIC B.2017.01935

19. Almakki A, Jumas-Bilak E, Marchandin H, LicznarFajardo P. Antibiotic resistance in urban runoff. Sci Total Environ. 2019;667:64-76. doi:10.1016/J.SCITOTE NV.2019.02.183

20. Berndtson AE. Increasing Globalization and the Movement of Antimicrobial Resistance between Countries. https://home-liebertpubcom.ezproxy.bu.edu/sur. 2020;21(7):579-585. doi:10.10 $\underline{\text { 89/SUR.2020.145 }}$

21. Penders J, Stobberingh EE, Savelkoul PHM, Wolffs PFG. The human microbiome as a reservoir of antimicrobial resistance. Front Microbiol. 2013;4(APR). doi:10.3389/FMICB.2013.00087 
22. Wang Y, Hu Y, Cao J, et al. Antibiotic resistance gene reservoir in live poultry markets. J Infect. 2019;78(6):445-453. doi:10.1016/j.jinf.2019.03.012

23. Elmund GK, Morrison SM, Grant DW, Nevins MP. Role of excreted chlortetracycline in modifying the decomposition process in feedlot waste. Bull Environ Contam Toxicol. 1971;6(2):129-132. doi:10.1007/BF01 $\underline{540093}$

24. Chen H, Zhang M. Occurrence and removal of antibiotic resistance genes in municipal wastewater and rural domestic sewage treatment systems in eastern China. Environ Int. 2013;55:9-14. doi:10.1016/ L.ENVINT.2013.01.019

25. Mutters NT, Bieber CP, Hauck C, Reiner G, Malek V, Frank U. Comparison of livestock-associated and health care-associated MRSA-genes, virulence, and resistance. Diagn Microbiol Infect Dis.

2016;86(4):417-421. doi:10.1016/j.diagmicrobio. 201 $\underline{6.08 .016}$

26. Salgado CD, Farr BM, Calfee DP. Communityacquired methicillin-resistant Staphylococcus aureus: A meta-analysis of prevalence and risk factors. Clin Infect Dis. 2003;36(2):131-139. doi:10.1086/345436

27. Mutatkar RK. Public health problems of urbanization. Soc Sci Med. 1995;41(7):977-981. doi:1 0.1016/0277-9536(94)00398-D

28. Winglee K, Howard AG, Sha W, et al. Recent urbanization in China is correlated with a Westernized microbiome encoding increased virulence and antibiotic resistance genes. Microbiome. 2017;5(1):1-13. doi:10.1186/S40168-017-0338-7

29. Gong P, Liang S, Carlton EJ, et al. Urbanisation and health in China. Lancet. 2012;379(9818):843-852. doi:10.1016/S0140-6736(11)61878-3

30. Jacobsen KH. Will COVID-19 generate global preparedness? Lancet. 2020;395(10229):1013-1014. $\underline{\mathrm{d}}$ oi:10.1016/S0140-6736(20)30559-6

31. Lancet T. COVID-19: fighting panic with information. Lancet (London, England). 2020;395(10224):537. doi:10.1016/S0140-6736(20)303 79-2

32. Su Z, Wen J, Abbas J, et al. A race for a better understanding of COVID-19 vaccine non-adopters. Brain, Behav Immun - Heal. 2020;9:100159. doi:10.101 6/I.BBIH.2020.100159

33. X Q, R R, Y W, et al. Fighting against the common enemy of COVID-19: a practice of building a community with a shared future for mankind. Infect Dis poverty. 2020;9(1). doi:10.1186/S40249-020-0065 $\underline{0-1}$
34. Knight GM, Glover RE, McQuaid CF, et al. Antimicrobial resistance and covid-19: Intersections and implications. Elife. 2021;10:1-27. doi:10.7554/ELI FE.64139

35. Pokharel S, Raut S, Adhikari B. Tackling antimicrobial resistance in low-income and middleincome countries. BMJ Glob Heal. 2019;4(6):e002104. doi:10.1136/BMJGH-2019-002104

36. Elton L, Thomason MJ, Tembo J, et al. Antimicrobial resistance preparedness in subSaharan African countries. Antimicrob Resist Infect Control. 2020;9(1):1-11. doi:10.1186/S13756-020-008 $\underline{00-Y}$

37. Dutescu IA. The Antimicrobial Resistance Crisis: How Neoliberalism Helps Microbes Dodge Our Drugs: https://doi.org/101177/0020731420949823. Published online August 16, 2020. doi:10.1177/00207314209498 $\underline{23}$

38. M A, C C, K S, et al. Averting the AMR crisis: What are the avenues for policy action for countries in Europe? Eur Obs Policy Briefs. Published online July 10, 2019. Accessed August 13, 2021. http://europepm c.org/books/NBK543406

39. Roskilde. How we are permanently destroying Gaza. Published online 2014

40. Genocide in Gaza: Physical destruction and beyond. Accessed August 13, 2021. https://mspace.li b.umanitoba.ca/handle/1993/34791

41. Abu Shaaban K. Quality Control Study on Some Essential Drugs Available on the Palestinian Drug Market. Published online 2009.

42. ABUALHASAN M, DWAIKAT S, ATAYA R, ALI A, AL-ATRASH M. Quality evaluation of iron-containing food supplements in the Palestinian market. Food Sci Technol. Published online June 11, 2021. doi:10.1590/ FST.01621

43. Eaton L. WHO calls for safety of health workers in Palestinian territories. BMJ. 2002;324(7339):698. o i:10.1136/BMI.324.7339.698/A

44. Gaza Strip - The World Factbook. Accessed August 13, 2021. https://www.cia.gov/the-world-factbook/co untries/gaza-strip/

45. Suisman D. The Arc: A Formal Structure for a Palestinian State. Rand Corp.; 2007. 
46. Displaced Palestine refugees seek shelter at UNRWA schools in Gaza - occupied Palestinian territory | ReliefWeb. Accessed August 13, 2021. http s://reliefweb.int/report/occupied-palestinian-territor $\mathrm{y} /$ displaced-palestine-refugees-seek-shelter-unrwa-s chools-gaza

47. Rapid Needs Assessment: Gaza May/June 2021 occupied Palestinian territory | ReliefWeb. Accessed August 13, 2021. https://reliefweb.int/report/occupie d-palestinian-territory/rapid-needs-assessment-gaz a-mayjune-2021

48. Cazabat C. The ripple effect: economic impacts of internal displacement. Intern Displac Monit Cent. 2018;(October):5. http://www.internal-displacemen t.org/sites/default/files/inline-files/20180608-idmc-ec onomic-impacts-framework.pdf

49. We must not ignore explosive weapons' environmental impact | CEOBS. Accessed August 13, 2021. https://ceobs.org/we-must-not-ignore-explosiv e-weapons-environmental-impact/

50. Thomas W. Victory by Duress: Civilian Infrastructure as a Target in Air Campaigns. http://dx.doi.org/101080/09636410600666238. 2010;15(1):1-33. doi:10.1080/09636410600666238

51. Weinthal E, Sowers J. Targeting infrastructure and livelihoods in the West Bank and Gaza. Int Aff. 2019;95(2):319-340. doi:10.1093/IA/IIZ015

52. Sowers J, Weinthal E. Humanitarian challenges and the targeting of civilian infrastructure in the Yemen war. Int Aff. 2021;97(1):157-177. doi:10.1093/I A/IIAA166

53. Falk R. Human Rights Situation in Palestine and Other Occupied Arab Territories. United Nations Gen Assemply. Published online 2009:649-655.

54. Mahase E. Gaza: Israeli airstrikes kill doctors and damage healthcare facilities. BMJ. 2021;373:n1300. $\underline{\mathrm{d}}$ oi:10.1136/BMI.N1300

55. David A, Artemis A, Raymond A, et al. C e p r.

56. Shomar B. The Gaza Strip: Politics and environment. Water Policy. 2011;13(1):28-37. doi:10.2 166/wp.2009.061

57. Basem S, Sami Abu F, Alfred Y. Assessment of Groundwater Quality in the Gaza Strip, Palestine Using GIS Mapping. J Water Resour Prot. 2010;2010(02):93-104. doi:10.4236/JWARP.2010.2201 1
58. Enshassi A. Environmental concerns for construction growth in Gaza Strip. Build Environ. 2000;35(3):273-279. doi:10.1016/S0360-1323(99)0001 7-7

59. Sarsour A. Impact of the last Israeli Military Operation on the Vital Environmental Sectors in Gaza Governorates, 2014. Accessed August 13, 2021. das-pa laestina-portal.de.http://www.das-palaestina-porta l.de/2014-gaza-Breif-report.doc

60. Map detail | UNITAR. Accessed August 13, 2021. ht tps://unitar.org/maps/map/2068

61. Salem M, Raab K, Wagner R. Solid waste management: The disposal behavior of poor people living in Gaza Strip refugee camps. Resour Conserv Recycl. 2020;153:104550. doi:10.1016/I.RESCONREC.2 019.104550

62. In refugee camps, limited resources lead to environmental degradation | The World from PRX. Accessed August 13, 2021. https://www.pri.org/storie s/2013-06-30/refugee-camps-limited-resources-leadenvironmental-degradation

63. Heckman JJ, Pinto R, Savelyev PA. WHO Public Health Assessment - Beit Lahia, March 2007. Published online 2007.

64. Ahmad NN. Gaza: A Case Study of Urban Destruction Through Military Involvement. Published online 2011.

65. Map detail | UNITAR. Accessed August 13, 2021. ht tps://unitar.org/maps/map/2068

66. Bazzi W, Abou Fayad AG, Nasser A, et al. Heavy Metal Toxicity in Armed Conflicts Potentiates AMR in A. baumannii by Selecting for Antibiotic and Heavy Metal Co-resistance Mechanisms. Front Microbiol. 2020;11:68. doi:10.3389/FMICB.2020.00068

67. Barnett ED, Weld LH, McCarthy AE, et al. Spectrum of Illness in International Migrants Seen at GeoSentinel Clinics in 1997-2009, Part 1: US-Bound Migrants Evaluated by Comprehensive ProtocolBased Health Assessment. Clin Infect Dis. 2013;56(7):913-924. doi:10.1093/CID/CIS1015

68. McCarthy AE, Weld LH, Barnett ED, et al. Spectrum of Illness in International Migrants Seen at GeoSentinel Clinics in 1997-2009, Part 2: Migrants Resettled Internationally and Evaluated for Specific Health Concerns. Clin Infect Dis. 2013;56(7):925-933. doi:10.1093/CID/CIS1016

69. Schnupf P, Gaboriau-Routhiau V, Cerf-Bensussan N. Modulation of the gut microbiota to improve innate resistance. Curr Opin Immunol. 2018;54:137-144. doi:10.1016/J.COI.2018.08.003 
70. Zeid S, Gilmore K, Khosla R, et al. Women's, children's, and adolescents' health in humanitarian and other crises. BMJ. 2015;351(January 2016):56-60. doi:10.1136/bmj.h4346

71. Olwedo MA, Mworozi E, Bachou H, Orach CG. Factors associated with malnutrition among children in internally displaced person's camps, northern Uganda. Afr Health Sci. 2008;8(4):244. Accessed August 13, 2021. https://www.ncbi.nlm.nih.gov/pmc/ articles/PMC2887019/

72. Hirani SAA, Richter S. Maternal and Child Health During Forced Displacement. J Nurs Scholarsh. 2019;51(3):252-261. doi:10.1111/JNU.12460

73. Christian P, Mullany LC, Hurley KM, Katz J, Black RE. Nutrition and maternal, neonatal, and child health. Semin Perinatol. 2015;39(5):361-372. doi:10.1 053/J.SEMPERI.2015.06.009

74. Katz J, Lee ACC, Kozuki N, et al. Mortality risk in preterm and small-for-gestational-age infants in lowincome and middle-income countries: a pooled country analysis. Lancet. 2013;382(9890):417-425. do $\mathrm{i}: 10.1016 / \mathrm{S} 0140-6736(13) 60993-9$

75. Walker SP, Chang SM, Powell CA, Simonoff E, Grantham-McGregor SM. Early Childhood Stunting Is Associated with Poor Psychological Functioning in Late Adolescence and Effects Are Reduced by Psychosocial Stimulation. J Nutr. 2007;137(11):2464-2469. doi:10.1093/IN/137.11.2464

76. Grantham-McGregor S, Cheung YB, Cueto S, Glewwe P, Richter L, Strupp B. Developmental potential in the first 5 years for children in developing countries. Lancet. 2007;369(9555):60-70. doi:10.1016/ S0140-6736(07)60032-4

77. Wells JC, Sawaya AL, Wibaek R, et al. The double burden of malnutrition: aetiological pathways and consequences for health. Lancet. 2020;395(10217):75-88. doi:10.1016/S0140-6736(19)3 2472-9

78. Bäckhed F, Roswall J, Peng Y, et al. Dynamics and Stabilization of the Human Gut Microbiome during the First Year of Life. Cell Host Microbe. 2015;17(5):690-703. doi:10.1016/J.CHOM.2015.04.004

79. Doak CM, Adair LS, Bentley M, Monteiro C, Popkin BM. The dual burden household and the nutrition transition paradox. Int J Obes. 2004;29(1):129-136. doi:10.1038/sj.ijo.0802824

80. Wells JCK. The capacity-load model of noncommunicable disease risk: understanding the effects of child malnutrition, ethnicity and the social determinants of health. Eur I Clin Nutr. 2018;72(5):688-697. doi:10.1038/s41430-018-0142-x
81. Kane AV, Dinh DM, Ward HD. Childhood malnutrition and the intestinal microbiome. Pediatr Res. 2014;77(1):256-262. doi:10.1038/pr.2014.179

82. Abuzerr S, Nasseri S, Yunesian M, et al.

Prevalence of diarrheal illness and healthcare-seeking behavior by age-group and sex among the population of Gaza strip: a community-based cross-sectional study. BMC Public Heal. 2019;19(1):1-10. doi:10.1186/ $\underline{\text { S12889-019-7070-0 }}$

83. Doan T, Worden L, Hinterwirth A, et al. Macrolide and Nonmacrolide Resistance with Mass Azithromycin Distribution. N Engl J Med. 2020;383(20):1941-1950. doi:10.1056/NEJMOA200260 $\underline{6}$

84. Ahiabu MA, Tersbøl BP, Biritwum R, Bygbjerg IC, Magnussen P. A retrospective audit of antibiotic prescriptions in primary health-care facilities in Eastern Region, Ghana. Health Policy Plan. 2016;31(2):250-258. doi:10.1093/HEAPOL/CZV048

85. Okeke IN, Lamikanra A, Edelman R. Socioeconomic and behavioral factors leading to acquired bacterial resistance to antibiotics in developing countries. Emerg Infect Dis. 1999;5(1):18-27. doi:10.3201/eid0501.990103

86. Shayan SI, Negarandeh R, Nazari R, Kiwanuka F, Rad SA. Self-medication with antibiotics in WHO Eastern Mediterranean Region: A Systematic Review and Meta-analysis. Published online 2019:1-22. doi:1 $0.21203 /$ rs.2.13620/v1

87. Al Baz M, Law MR, Saadeh R. Antibiotics use among Palestine refugees attending UNRWA primary health care centers in Jordan - A cross-sectional study. Travel Med Infect Dis. 2018;22:25-29. doi:10.10 16/J.TMAID.2018.02.004

88. Krishnan G, Horst GL, Shea PJ. Differential Tolerance of Cool- and W arm-Season Grasses to TNT -Contaminated Soil. http://dx.doi.org/101080/ 15226510008500045. 2006;2(4):369-382. doi:10.1080/ 15226510008500045

89. EL R, MV B, A B, A L, SE S, NC B. Engineering plants for the phytoremediation of RDX in the presence of the co-contaminating explosive TNT. New Phytol. 2011;192(2):405-413. doi:10.1111/J.1469-813 7.2011.03807.X

90. Sommer F, Bäckhed F. The gut microbiota masters of host development and physiology. Nat Rev Microbiol. 2013;11(4):227-238. doi:10.1038/nrmicro29 $\underline{74}$ 
91. Jakobsson HE, Rodríguez-Piñeiro AM, Schütte A, et al. The composition of the gut microbiota shapes the colon mucus barrier. EMBO Rep.

2015;16(2):164-177. doi:10.15252/EMBR.201439263

92. World Health Organization IO for M y G de E. Health of Migrants - The Way Forward: Report of a Global Consultation.; 2010. Accessed August 13, 2021. https://www.who.int/hac

93. Häsler R, Kautz C, Rehman A, et al. The antibiotic resistome and microbiota landscape of refugees from Syria, Iraq and Afghanistan in Germany. Microbiome. 2018;6(1):1-11. doi:10.1186/S40168-018-0414-7

94. Angeletti S, Ceccarelli G, Vita S, et al. Unusual microorganisms and antimicrobial resistances in a group of Syrian migrants: Sentinel surveillance data from an asylum seekers centre in Italy. Travel Med Infect Dis. 2016;14(2):115-122. doi:10.1016/J.TMAID.2 016.03.005

95. Rafei R, Dabboussi F, Hamze M, et al. First report of blaNDM-1-producing Acinetobacter baumannii isolated in Lebanon from civilians wounded during the Syrian war. Int J Infect Dis. 2014;21:21-23. doi:1 $\underline{0.1016 / I . I J I D .2014 .01 .004}$

96. Nellums LB, Thompson H, Holmes A, et al. Antimicrobial resistance among migrants in Europe: a systematic review and meta-analysis. Lancet Infect Dis. 2018;18(7):796-811. doi:10.1016/S1473-3099(1 8)30219-6
97. Vonaesch P, Anderson M, Sansonetti PJ. Pathogens, microbiome and the host: Emergence of the ecological Koch's postulates. FEMS Microbiol Rev. 2018;42(3):273-292. doi:10.1093/femsre/fuy003

98. Minssen T, Outterson K, Katwyk SR Van, et al. Social, cultural and economic aspects of antimicrobial resistance. Bull World Health Organ. 2020;98(12):823. doi:10.2471/BLT.20.275875

99. Tompson AC, Chandler CI. Addressing antibiotic use: insights from social science around the world. London Sch Hyg Trop Med. Published online 2021. do i:10.17037/PUBS.04659562

100. UNHCR - Urban Refugees. Accessed July 9, 2021. https://www.unhcr.org/urban-refugees.html

101. Jacobsen K. Refugees and Asylum Seekers in Urban Areas: A Livelihoods Perspective. J Refug Stud. 2006;19(3):273-286. doi:10.1093/JRS/FEL017

102. UN Shared Rohingya Data Without Informed Consent | Human Rights Watch. Accessed July 9, 2021. https://www.hrw.org/news/2021/06/15/un-shared-roh ingya-data-without-informed-consent

103. Bokhary H, Pangesti KNA, Rashid H, Ghany MA El, Hill-Cawthorne GA. Travel-Related Antimicrobial Resistance: A Systematic Review. Trop Med Infect Dis. 2021;6(1):11. doi:10.3390/TROPICALMED6010011 